\title{
FUNDAMENTAL ASPECTS OF A THIRD COMPONENT USED IN TERNARY SOLID DISPERSION: A REVIEW
}

\author{
SREE VARSHINI $\mathbf{S}^{{ }^{*}}$, VAIYANA RAJESH C ${ }^{1}$ \\ Department of Pharmaceutics, PSG College of Pharmacy, Coimbatore 641004, Tamilnadu, India \\ Email: varsha291296@gmail.com
}

Received: 27 Jan 2021, Revised and Accepted: 13 Mar 2021

\begin{abstract}
Ternary solid dispersion (TSD) is one of the promising approaches used in recent studies to address the issues encountered by poorly water-soluble drugs. The binary solid dispersion (BSD) with the drug and the single polymer is not sufficient to satisfy all the criteria such as improved solubility, dissolution, stability, supersaturation, and recrystallization inhibition. Hence, the TSD with the third component/ternary agent aids in overcoming the limitations, thereby enhancing the solubility and bioavailability to a greater extent when compared to the BSD. Excipients that can be used as a third component includes surfactants, pH modulator, polymer and adsorbents. All these excipients have distinct benefits in improving the efficiency of the final dosage form. However, care must be taken in selecting suitable excipients for the research. This review highlights the impact of these excipients in improving the formulation complications and the therapeutic potential of the TSD.
\end{abstract}

Keywords: Ternary solid dispersion, Ternary agent, Surfactant, pH modulator, Adsorbent, Polymer

(C) 2021 The Authors. Published by Innovare Academic Sciences Pvt Ltd. This is an open access article under the CC BY license (https://creativecommons.org/licenses/by/4.0/] DOI: https://dx.doi.org/10.22159/ijap.2021v13i3.40890. Journal homepage: https://innovareacademics.in/journals/index.php/ijap

\section{INTRODUCTION}

Solubility, as well as dissolution, is a fundamental principle across every physicochemical science, including biopharmaceutical and pharmacokinetic aspects of any medicine's therapy [1]. In recent decades, novel drugs with extraordinary medicinal benefits generated by various research activities entering the drug development phase are diminishing, due to their non-optimal biopharmaceutical properties $[1,2]$. The foremost obstacle in the drug development phase is limited to the solubility/dissolution of the drugs in aqueous media. Since the drug must be bioavailable for the patient to exert its action, at a certain point of time, the drug must be completely dissolved or solubilized within the body fluid, regardless of the route of administration [3]. These complications significantly affect the pharmacokinetic parameter such as absorption, distribution, metabolism and excretion of the drug [4]. The primary objective of improving the solubility/dissolution is to enhance the bioavailability of the drug. The low solubility and dissolution rate of Active Pharmaceutical Ingredient (API) in G. I. T fluid also lead to inadequate bioavailability, increased dosage, and blood concentration variability [5]. Class II and Class IV drugs with low solubility in the Biopharmaceutical Classification System (BCS) suffer from dissolution-related absorption issues. Specific methods to resolve low solubility include chemical and physical alteration of drug candidates [6]. The Noyes-Whitney equation shows that the rate of dissolution of a drug is proportional to both the concentration gradient and the surface area of particles. Increasing the surface area of the substance will, therefore, increase the dissolution rate [7]. Several methods, such as solid dispersion (SD) [8-11], complexation $[12,13]$, lipid-based systems [14, 15], micronization $[16,17]$, nanonization $[18,19]$ and co-crystals $[20,21]$ were already suggested to increase the solubility of poorly watersoluble drugs. Among them, SD technology, which involves dispersing drugs in different types of polymers, is commonly used to improve solubility and bioavailability [22]. In 1961, the SD principle was introduced by Sekiguchi $\mathrm{K}$ and Obi $\mathrm{N}$ [23]. Conventional BSD involves dispersing the drug into a single polymer or surfactant or any other additive, thereby enhancing the solubility of the drug [24]. It is known that the solid-state of the product may be either crystalline or amorphous, which varies with the energetical state of solid-packed molecules [25]. The state at which the drug is dispersed in the crystalline or amorphous carrier has a significant impact on solubility and drug release [26]. Although there have been consistent reports of the utilization of
SD's in the pharmaceutical literature, only a few commercial products depend on the SD method [27]. An ideal formulation must be stable, prevent recrystallization, enhance the super saturation and dissolution properties of the drug. BSD may not be adequate for meeting all the criteria listed above [28]. Therefore, TSD can be an efficient technique for combating specific limitations of BSD [29]. TSD was formerly known as a multicomponent SD, which involves the addition of a third component other than the drug and a carrier (i.e., API, polymer and an additive) that would further enhance the efficiency of SD [30]. Adding a third component (ternary agent) to produce a TSD system gives improved stability, greater miscibility, stronger intermolecular interactions, significantly higher water-solubility, and synergistic benefit in all of these factors compared to the BSDs [31]. The carrier used in combination with a ternary agent could be a polymer, surfactant or a polymer with surfactant property $[32,33]$. Examples of ternary agents comprise surfactant [34], polymer [35], adsorbent [36], pH modulator [37] and hydrotropic agent [38]. Various international publications of the past decade are summarized from the reputed source (Elsevier, Pubmed, NCBI) to emphasize the significance of the key components (ternary agents) particularly, surfactants, polymers, $\mathrm{pH}$ modulators, and adsorbents to improve TSD's reliability in addressing the challenges of formulation associated with the drug solubility and dissolution.

Surface active agents (surfactants)

Surfactants are commonly used in the TSD along with the carrier as it provides multiple benefits. In general, the drug should reside in a supersaturated state to reach the optimum rate of dissolution. The addition of surfactants as a ternary agent results in the formation of complex micelles and promotes supersaturation of the drug [39]. Additionally, it provides improved stability and prevents the precipitation of the drug [40]. In TSD, the surfactant along with the carrier act by reducing the surface tension at the interface thereby alters the nature of the drug and enhances dissolution [41]. The Surfactant acts as a wetting agent [42], plasticizer [43], crystallization inhibitor [44], and stabilizer [45] with respect to dissolution properties [46]. Critical micellar concentration (CMC) and hydrophilic-lipophilic balance (HLB) play a key role in the dissolution of the drug [47]. When the concentration of the surfactant is greater than CMC, it aids in the improved dissolution by forming micelles/inhibiting precipitation and while lesser than CMC acts by reducing the interfacial tension [48-50]. Based on the polarity, surfactants are classified into. 
- Non-ionic surfactants: Poloxamer, Polysorbates, Brij L4

- Anionic surfactants: Sodium Lauryl Sulfate (SLS)/Sodium Dodecyl Sulfate (SDS)

- Cationic surfactants: Cetrimide, Benzalkonium chloride

- Amphoteric/Zwitterionic surfactants: Tocopheryl Polyethylene Glycol Succinate (TPGS)/Vitamin-E TPGS, Poloxamers, SLS

The surfactants recently used in combination with carriers in TSD are poloxamer (Pluronic), SLS, and D- $\alpha$-TPGS/Vitamin E TPGS. It is reported that the combination of poloxamer 188 and Polyvinyl Pyrrolidone (PVP) K30 showed a beneficial impact on solubility, stability, in vitro dissolution, and bioavailability of Febuxostat [51]. The addition of surfactants could be either intra-granular or extra-granular. When mixed intra-granularly with the API and polymer the surfactants have a beneficial effect on the rate of drug release rather than extra-granularly applied [52]. A study documented the effect of surfactant added internally and externally to indomethacin and PVP. Internally incorporated SLS had a dramatic effect on the release of indomethacin as compared with externally added SLS [49]. Past studies on the Surfactantcarrier combination used in TSD are enlisted in table 1.

Table 1: Studies on the surfactant-carrier combination used in TSD

\begin{tabular}{|c|c|c|c|c|}
\hline API & Surfactant & Carrier & Impact of surfactant on TSD & Ref \\
\hline Domperidone & Poloxamer 188 & Gelucire 50/13 & $\begin{array}{l}\text { Poloxamer } 188 \text { was found to be an ideal ternary agent than poloxamer } 407 \\
\text { as it exhibited better dissolution of domperidone. }\end{array}$ & [53] \\
\hline Ezetimibe & Poloxamer 188 & PVP K30 & $\begin{array}{l}\text { Melt quenching of Poloxamer } 188 \text { with ezetimibe exhibited enhanced } \\
\text { solubility as well supersaturation in the bio-relevant media. }\end{array}$ & [54] \\
\hline Diacerein & Pluronic F-68 & PEG 4000 & $\begin{array}{l}\text { Pluronic F-68 in TSD enhanced the solubility of diacerein by micellar } \\
\text { solubilization and increased steric hindrance. }\end{array}$ & [55] \\
\hline Domperidone & Pluronic F-127 & PVP K30 & $\begin{array}{l}\text { The interfacial tension between the drug and the dissolution medium was } \\
\text { minimized by surfactant in TSD which resulted in increased wettability and } \\
\text { thus enhancing domperidone dissolution. }\end{array}$ & [56] \\
\hline LW6 & Poloxamer 407 & Povidone K30 & $\begin{array}{l}\text { The presence of poloxamer } 407 \text { in TSD resulted in improved solubility by } \\
\text { micelle formation and delivering the drug into the core of micelles. }\end{array}$ & [57] \\
\hline Manidipine & TPGS & Copovidone & $\begin{array}{l}\text { Due to its low CMC, TPGS decreased the interfacial tension and also showed a } \\
\text { more porous structure resulting in the improved dissolution of manidipine. }\end{array}$ & [58] \\
\hline Valsartan & TPGS & Soluplus & $\begin{array}{l}\text { The presence of TPGS as a plasticizer in the TSD resulted in reduced glass } \\
\text { transition temperature and also enhanced penetration of the valsartan } \\
\text { through the mucosal membrane. }\end{array}$ & [59] \\
\hline Lacidipine & SDS & Soluplus & $\begin{array}{l}\text { The Ternary system with SDS not only enhanced the solubility and } \\
\text { dissolution but also improved the bioavailability of lacidipine up to } 3.7 \\
\text { folds when compared to the binary system. }\end{array}$ & [60] \\
\hline Felodipine & SDS & Soluplus & $\begin{array}{l}\text { By acting as a plasticizer, crystallization inhibitor, a driving force to assist the } \\
\text { carrier, SDS offered many advantages and resulted in enhanced dissolution. }\end{array}$ & [61] \\
\hline Chlorthalidone & SLS & Soluplus & $\begin{array}{l}\text { The presence of SLS above the CMC of } 2 \% \text {, significantly enhanced the } \\
\text { solubility up to } 5.5 \text { times than the pure drug. }\end{array}$ & [62] \\
\hline
\end{tabular}

\section{pH modulators}

In general, water-insoluble drugs are weakly acidic or weakly basic compounds in nature. Hence, they mostly dependent upon the $\mathrm{pH}$ for their solubility. An approach to modify the release rate of numerous $\mathrm{pH}$-dependent drugs is to modulate the $\mathrm{pH}$ of the formulation known as microenvironmental $\mathrm{pH}$ [63]. Weakly acidic drugs show greater solubility at neutral or alkaline $\mathrm{pH}$ and weakly basic drugs show improved solubility at acidic $\mathrm{pH}$ [64]. The dissolution behavior can be closely associated with the microenvironmental $\mathrm{pH}$ at the diffusion layer. $\mathrm{pH}$ modifying agents act by altering the $\mathrm{pH}$ through intermolecular hydrogen bonding with the drug and thereby decreasing the crystallinity of the drug resulting in an enhanced release rate [65]. Alkalizers [66] or Acidifiers [67] are the agents that can be used for altering the microenvironment $\mathrm{pH}$ i.e. either by increasing or lowering the $\mathrm{pH}$ at which the drug could dissolve easily.
Alkalizers are added to weakly acidic drugs and for weakly basic drugs acidifiers are added. The Conventional BSD technique alone is not sufficient for all pH-dependent drugs as it is restricted to the solubilization capacity [63]. Past studies stated that combining a $\mathrm{pH}$ modulator along with a carrier in TSD could effectively enhance the various properties of the drugs [68-70]. A study reported that combining alkalizer with kollidon VA64 and glycyrrhetinic acid (GA), resulted in the enhanced dissolution of GA through the formation of ion complexes by strong electrostatic attraction [71]. Using citric acid (acidifier) along with Amorphous Solid Dispersion (ASD) technology significantly enhanced the absorption of Carvedilol even under elevated gastric $\mathrm{pH}$ conditions [72]. Some of the most commonly used alkalizers include Aminoclay, $\mathrm{NaOH}, \mathrm{Na}_{2} \mathrm{CO}_{3}, \mathrm{Ca}(\mathrm{OH})_{2}, \mathrm{NaHCO}_{3}$, and Meglumine. Acidifiers generally used in TSD include citric acid, succinic acid, fumaric acid, and tartaric acid. Past studies on the $\mathrm{pH}$ modulator-carrier combination used in TSD are enlisted in table 2.

Table 2: Studies on pH modulator-carrier combination used in TSD

\begin{tabular}{|c|c|c|c|c|}
\hline API & pH modulator & Carrier & Impact of pH modulator on TSD & Ref \\
\hline \multicolumn{5}{|l|}{ Alkalizers } \\
\hline Chrysin & Aminoclay & Brij L4 & $\begin{array}{l}\text { Chrysin (pKa 6.72) was found to be more soluble in the basic environment. Adding } \\
\text { aminoclay increased the SD's microenvironment } \mathrm{pH} \text { to the basic state, thus } \\
\text { increasing the dissolution. }\end{array}$ & [73] \\
\hline Telmisartan & $\mathrm{NaOH}$ & Soluplus & $\begin{array}{l}\text { Among various alkalizer, } \mathrm{NaOH}(1 \%) \text { had a beneficial impact on Telmisartan solubility } \\
\text { by providing a continuous } \mathrm{pH} \text { adjustment throughout the dispersion matrix. }\end{array}$ & [74] \\
\hline Nateglinide & $\mathrm{Na}_{2} \mathrm{CO}_{3}$ & $\begin{array}{l}\text { Poloxamer } \\
188\end{array}$ & $\begin{array}{l}\text { The presence of } \mathrm{Na}_{2} \mathrm{CO}_{3} \text { deprotonated the nateglinide carbonyl group, resulting in } \\
\text { pH-independent solubility in the acid environment, improving the bioavailability of } \\
\text { nateglinide by up to four-folds. }\end{array}$ & [75] \\
\hline Toltrazuril & $\mathrm{Ca}(\mathrm{OH})_{2}$ & PVP & $\begin{array}{l}\text { With the increase in the } \mathrm{Ca}(\mathrm{OH}) 2 \text { ratio, the rate of dissolution of toltrazuril was } \\
\text { found to be enhanced, as it facilitates intermolecular interaction with Toltrazuril } \\
\text { which is necessary for the maintenance of supersaturation. }\end{array}$ & [76] \\
\hline Clarithromycin & $\mathrm{NaHCO}_{3}$ & $\begin{array}{l}\text { HPMC/ } \\
\text { PVP }\end{array}$ & $\begin{array}{l}\text { The Clarithromycin would have been degraded by acidic media after } 60 \text { min before } \\
\text { leaving the tablet if, } \mathrm{NaHCO}_{3} \text { were not added. The alkalizer increased the dissolution } \\
\text { and stability of the drug without altering the crystallinity of the drug. }\end{array}$ & [77] \\
\hline
\end{tabular}




\begin{tabular}{|c|c|c|c|c|}
\hline Telmisartan & Meglumine & $\begin{array}{l}\text { PVP } \\
\text { K-30 }\end{array}$ & $\begin{array}{l}\text { Since meglumine was a strong metal oxide it had a higher } \mathrm{pH} \text { value than other } \\
\text { alkalizers and by forming a salt with telmisartan, it increased dissolution in the } \\
\text { intestinal fluid. }\end{array}$ & [78] \\
\hline \multicolumn{5}{|c|}{ (2, } \\
\hline GT0918 & Citric Acid & $\begin{array}{l}\text { PVP } \\
\text { K-30 }\end{array}$ & $\begin{array}{l}\text { Citric acid aids in preventing the recrystallization of an ASD system and potentially } \\
\text { enhances the dissolution by hydrogen bonding between the drug and the } \mathrm{pH} \\
\text { modifier. }\end{array}$ & [79] \\
\hline Aripiprazole & Succinic acid & $\begin{array}{l}\text { Kollidon- } \\
12 \mathrm{PF} \\
\text { (PVP) }\end{array}$ & $\begin{array}{l}\text { SD with a concentration of } 10 \% \text { succinic acid enhanced the solubility and drug } \\
\text { release compared to the SD without the acidifier by maintaining the optimal pH near } \\
\text { the aripiprazole. }\end{array}$ & [80] \\
\hline Raloxifene $\mathrm{HCl}$ & Fumaric acid & HPMC & $\begin{array}{l}\text { Raloxifene } \mathrm{HCl} \text { and fumaric acid in SD resulted in salt formation by hydrogen } \\
\text { bonding which significantly increased the solubility and dissolution of raloxifene } \\
\mathrm{HCl} \text {. }\end{array}$ & [81] \\
\hline Dipyridamole & Tartaric acid & $\begin{array}{l}\text { Eudragit } \\
\text { S100 }\end{array}$ & $\begin{array}{l}\text { Though surrounded by enteric polymer, electrostatic interaction between tartaric } \\
\text { acid and dipyridamole resulted in a change of microenvironment } \mathrm{pH} \text { facilitating a } \\
\text { rapid dissolution of dipyridamole. }\end{array}$ & [82] \\
\hline
\end{tabular}

\section{Polymer-polymer TSD}

Even though crystalline drugs offer the advantage of high purity and stability, their solubility is limited due to high lattice energy. On the contrary, the amorphous form depicts a disordered texture with high free energy that contributes to greater apparent solubility than its crystalline counterpart [83, 84]. Thus, the Amorphous Ternary Solid Dispersion (ATSD) has gained more attention in enhancing the solubility and dissolution properties of many poorly water-soluble drugs [85]. However, the pharmaceutical benefit of amorphous drugs is impaired by their low thermodynamic stability and their susceptibility to readily recrystallize in the solid-state or else during dissolution [86]. Retaining a drug in the amorphous state in both solid and solution phases is vital. The polymer prevents crystal growth by raising the glass transition temperature and decreasing the molecular mobility of the amorphous drug [87]. The polymer retains the supersaturated state of the drug by forming an intermolecular interaction with them [88]. The BSD with a drug and single polymer may be inadequate to satisfy all the criteria. Hence, the ATSD with polymer as the third component (ternary agent) is used to obtain optimum solubility and dissolution of poorly watersoluble drugs [89]. TSD of Itraconazole with a combination of polymeric carriers such as HPMCP and soluplus prepared by hotmelt extrusion significantly improved solubility and bioavailability and also retained the physical stability of the formulation [90]. PVP K30 was inefficient in preserving the supersaturated state of the drug, whereas Soluplus played an integral part in sustaining its longterm supersaturation. Thus, PVP K30 and Soluplus had a synergistic effect for improving TEL's solubility and dissolution [91]. Some of the most commonly used combinations of polymers include HPMC, PVP (Kollidon), Eudragid, PLGA, and Soluplus. Past research on the combination of polymers used in TSD is shown in table 3.

Table 3: Studies on the polymer-polymer combination used in TSD

\begin{tabular}{|c|c|c|c|c|}
\hline API & Polymer & Carrier & Impact of polymers on TSD & Ref \\
\hline Indomethacin & Eudragid E100 & PVP K90 & $\begin{array}{l}\text { The SD was stabilized by Eudragid E100 and the supersaturation was retained by PVP } \\
\text { K30 and the mixture of both had a synergistic effect on the indomethacin dissolution. }\end{array}$ & [29] \\
\hline Celecoxib & HPMCAS & $\begin{array}{l}\text { Polyvinyl } \\
\text { alcohol }\end{array}$ & $\begin{array}{l}\text { Pre-dissolved HPMCAS as a powder extended the supersaturation by inhibiting } \\
\text { growth over the dissolution period by maintaining the particle size. }\end{array}$ & [89] \\
\hline Ibuprofen & НРМСР-НР55 & $\begin{array}{l}\text { Kollidon } \\
\text { VA64 }\end{array}$ & $\begin{array}{l}\text { By acting as an anti-plasticizer, HPMCP HP55 increased stability and kollidon VA64 } \\
\text { improved the dissolution rate by increasing API wettability. }\end{array}$ & [92] \\
\hline Griseofulvin & Soluplus & $\begin{array}{l}\text { Kollidon } \\
\text { VA64 }\end{array}$ & $\begin{array}{l}\text { Soluplus as a major component inhibited the crystal growth and a minor component } \\
\text { VA64 increased the wettability resulting in a rapid release of griseofulvin. }\end{array}$ & [93] \\
\hline Dipyridamole & HPMC K100 & PVP K30 & $\begin{array}{l}\text { PVP K30 and HPMC K100 had a synergistic impact on the solid-state property and } \\
\text { dissolution of both dipyridamole and cinnarizine by maximum supersaturation } \\
\text { concentration and crystallization inhibition. }\end{array}$ & {$[94]$} \\
\hline API & PVP & PLGA & $\begin{array}{l}\text { PLGA sustained the release of the formulation by forming a phase-separated surface } \\
\text { layer and PVP enhanced the solubility and dissolution of the API from the SD. }\end{array}$ & [95] \\
\hline Clopidogrel & HPMC & PVP & $\begin{array}{l}\text { The physical stability and oral bioavailability of the drug with low glass transition } \\
\text { temperature is improved by a combination of HPMC and PVP. }\end{array}$ & [96] \\
\hline Celecoxib & HPMC E5 & PVP K30 & $\begin{array}{l}\text { The combination of PVP-HPMC prevented recrystallization and considerably improved } \\
\text { the dissolution of celecoxib compared to the SD prepared with PVP or HPMC alone. }\end{array}$ & [97] \\
\hline Griseofulvin & $\begin{array}{l}\text { Eudragit } \\
\text { L100 }\end{array}$ & HPMC & $\begin{array}{l}\text { As compared to the BSD of individual polymer(s), the TSD substantially increased the } \\
\text { supersaturation of griseofulvin. The desired dissolution of griseofulvin is } \\
\text { accomplished by the additional benefits of polymer blends. }\end{array}$ & [98] \\
\hline
\end{tabular}

\section{Adsorbents}

Despite several advantages, TSD has certain drawbacks due to its handling and stability issues. TSD formulation often results in a waxy yield, and this is due to the carrier's nature. As a result, they tend to have a poor flow, poor compressibility, and hard to pulverize [99, 100]. To resolve these problems, inert material with good flow and compressibility should be used to absorb the dispersion on its surface [101]. Moreover, adsorption carriers not only prevent the crystal growth due to confined space within the pores of carriers but also stabilize the drug in the TSD by various chemical interactions [102]. Previous research has suggested that the adsorption carriers (sylysia
350) can be used as a ternary agent in addition to their antiplasticizing effect in the ATSD of itraconazole [103]. Another study stated that using neusilin US2, as an adsorbent effectively turned viscous semisolid substance into a free-flowing powder so that it can be compressed into a tablet or filled into the capsule as powders [104]. The presence of neusilin US2 not only resolved the issue of TPGS's stickiness but also enhanced the ticagrelor flow property and the study revealed that the use of neusilin US2 in TSD preparation would improve industrial processes [105]. Some of the adsorbent widely used are sylysia $350[106,107]$, neusilin $[108,109]$, Aerosil $[110,111]$, Lactose [112, 113], Florite [114]. Past studies on the adsorbent-carrier combination used in TSD are enlisted in table 4. 
Table 4: Studies on adsorbent-carrier combination used in TSD

\begin{tabular}{|c|c|c|c|c|}
\hline API & Adsorbent & Carrier & Impact of adsorbents on TSD & Ref \\
\hline Valsartan & Lactose & Gelucire 50/13 & $\begin{array}{l}\text { Increased quantity of lactose addition resulted in free-flowing powder with } \\
\text { reproducible dissolution characteristics. }\end{array}$ & [100] \\
\hline Bosentan & Sylysia 350 & Poloxamer 188 & $\begin{array}{l}\text { The inclusion of Sylysia } 350 \text { turned the waxy SD into a free-flowing powder } \\
\text { with adequate compressibility and also expanded the surface area, resulting in } \\
\text { rapid drug desorption. }\end{array}$ & [101] \\
\hline $\begin{array}{l}\text { Cefuroxime } \\
\text { axetil }\end{array}$ & Sylysia 350 & Gelucire 50/13 & $\begin{array}{l}\text { The benefits of adding sylysia } 350 \text { are better yield, inhibition of } \\
\text { recrystallization, flowability, an increase in the effective surface area, and } \\
\text { amorphous state preservation. }\end{array}$ & [106] \\
\hline Celecoxib & Neusilin US2 & $\begin{array}{l}\text { Phosphatidylcholine } \\
\text { (PC) }\end{array}$ & $\begin{array}{l}\text { As the PC-based SD exhibited a lipidic consistency, it was challenging } \\
\text { to formulate it into an oral dosage form. The flowability of the SD was } \\
\text { improved by adding an adsorbent. }\end{array}$ & [107] \\
\hline Carbamazepine & Neusilin UFL2 & Kollidon VA64 & $\begin{array}{l}\text { Together with the carrier, Neusilin UFL2 improved the dissolution by } \\
\text { increasing the surface area and carbamazepine flowability. }\end{array}$ & [108] \\
\hline Curcumin & Aerosil & Gelucire 50/13 & $\begin{array}{l}\text { Due to the hydrogen bonding between the drug and the carrier and its surface } \\
\text { adsorption onto the aerosil, the TSD was found to be stable for around } 9 \text { mo. }\end{array}$ & [109] \\
\hline Nifedipine & Aerosil 200 & Eudragit E & $\begin{array}{l}\text { The absence of adsorbent resulted in a gelatinous mass, while free-flowing } \\
\text { powder was observed along with a significant increase in dissolution in the } \\
\text { presence of Aerosil } 200 \text {. }\end{array}$ & [110] \\
\hline Gliclazide & Lactose & $\begin{array}{l}\text { Poloxamer/ } \\
\text { PEG }\end{array}$ & $\begin{array}{l}\text { Complete desorption of gliclazide resulted in rapid dissolution by the } \\
\text { combined effect of adsorption and reduction in size. }\end{array}$ & [111] \\
\hline $\begin{array}{l}\text { Lurasidone } \\
\text { hydrochloride }\end{array}$ & Florite & Poloxamer 188 & $\begin{array}{l}\text { Florite prevented the transformation of an amorphous form to a crystalline } \\
\text { and increased the stability of the amorphous state. }\end{array}$ & [112] \\
\hline
\end{tabular}

\section{CONCLUSION}

Various additives are used as a third component to overcome the limitations associated with BSD. These additives improve the efficiency of TSD as a formulation through several strategies. For example, surfactants along with the carrier act by distinct mechanisms such as reducing the surface tension, preventing recrystallization, maintenance of supersaturation and also improves the physical stability of the drug. CMC and HLB are the important variables to be considered when selecting a surfactant for the study. Therefore, care must be taken in choosing suitable surfactants. For drugs that depend on the $\mathrm{pH}$ for their solubility, $\mathrm{pH}$ modulators are the appropriate choice of excipients. Alkalizers/acidifiers aids in solubility and dissolution of weakly acidic/weakly basic drugs by modulating the microenvironment $\mathrm{pH}$ at which the drug dissolves easily.

They also assist in supersaturation by establishing an intermolecular interaction with the drug. Additionally, $\mathrm{pH}$ modulators improved stability without altering the nature of the formulation. The amorphous form of the drug offers improved apparent solubility than its crystalline counterpart owing to its high free energy. Since the ATSDs are thermodynamically unstable and more liable to recrystallization, it is vital to maintain them in the amorphous state. The polymer-polymer combination aids in maintaining the super saturation, inhibiting the crystal growth, and improved the stability of the ATSD. Despite enormous benefits, the commercial use of SD is limited due to the complexity of handling and scale-up. To overcome these obstacles, adsorbents are added to the TSD as a third component. These adsorbents convert the waxy SD into a free-flowing powder so that it can be compressed into a tablet or powder that can be filled into the capsule. Every excipient has both benefits and drawbacks, so caution should be given to selecting the appropriate excipient for the research. It is therefore concluded that the addition of different additives as a third component improves TSD's efficacy in enhancing the solubility, dissolution, and bioavailability of poorly water-soluble drugs.

\section{FUNDINGS}

Nil

\section{AUTHORS CONTRIBUTIONS}

All the authors contributed equally.

\section{CONFLICTS OF INTERESTS}

Declared none

\section{REFERENCES}

1. Thorat YS, Gonjari ID, Hosmani AH. Solubility enhancement techniques: a review on conventional and novel approaches. Int J Pharm Sci Res 2011;2:2501-13.

2. Bermudez JM, Cid AG, Simonazzi A, Palma SD. Solid dispersion technology as a strategy to improve the bioavailability of poorly soluble drugs. Ther Delivery 2019;10:363-82.

3. Goke K, Lorenz T, Repanas A, Schneider F, Steiner D, Baumann K, et al. Novel strategies for the formulation and processing of poorly water-soluble drugs. Eur J Pharm Biopharm 2017;126:40-56.

4. Bhusnure OG, Yogita M, Gholve SS, Sidram GP, Thonte SS, Formulation and evaluation of poorly aqueous soluble drug by solid dispersion method. J Pharm Res 2016;10:33-40.

5. Krishnamoorthy V, Nagalingam A, Prasad VPR, Parameshwaran S, George N, Kaliyan P. Characterization of olanzapine-solid dispersions. Iran J Pharm Res 2011;10:13-23.

6. Jagtap S, Magdum C, Jadge D, Jagtap R. Solubility enhancement technique: a review. J Pharm Sci Res 2018;10:2205-11.

7. Macheras P, Dokoumetzidis A. A century of dissolution research: from Noyes and Whitney to the Biopharmaceutics classification system. Int J Pharm 2006;321:1-11.

8. Gowda DV, Sehgal N, Gupta NV, Sivadasu P. Fabrication and evaluation of solid dispersion containing glibenclamide. Asian J Pharm Clin Res 2018;11:158-61.

9. Alhammid SNABD, Abduljabbar HH. Enhancement of the solubility and the dissolution rate of tamoxifen citrate solid dispersion using soluplus by solvent evaporation technique, Asian J Pharm Clin Res 2019;12:216-21.

10. Wu G, Huang BB, Liu DX, Liu DK. Application of solid dispersion technique to improve solubility and sustain release of emamectin benzoate. Molecules 2019;24:4315.

11. Pawar P, Patil M, Waydande S. Design and evaluation of topical solid dispersion composite of voriconazole for the treatment of ocular keratitis. Ther Delivery 2019;10:481-92.

12. Salami M, Mohammadian M, Momen S, Alavi F, Djomeh ZE, Movahedi AAM. Enhancing the aqueous solubility of curcumin at acidic conditions through the complexation with whey protein nanofibrils. Food Hydrocolloids 2019;87:902-14.

13. Sosnik A, Kuplennik N. Enhanced nanoencapsulation of sepiapterin within PEG-PCL nanoparticles by complexation with triacetyl-beta-cyclodextrin. Molecules 2019;24:2715.

14. Williams HD, Porter CJH, Speybroeck MV, Augustijns P. Lipidbased formulations solidified via adsorption onto the mesoporous carrier neusilin R-US2: effect of drug type and formulation composition on in vitro pharmaceutical performance. J Pharm Sci 2014;103:1734-46. 
15. Kazi M, Amri KAA, Alanazi FK. The role of lipid-based drug delivery systems for enhancing solubility of highly selective antiviral agent acyclovir. Pharm Dev Technol 2015;22:312-21.

16. Herpin MJ, Smyth HDC. Super-heated aqueous particle engineering (SHAPE): a novel method for the micronization of poorly water-soluble drugs. J Pharm Invest 2017;48:135-42.

17. Seo B, Kim T, Park HJ, Lee JM, Lee YW, Kim JY. Extension of the hansen solubility parameter concept to the micronization of Cyclotrimethylenetrinitramine crystals by the supercritical anti-solvent process. J Supercrit Fluids 2016;111:112-20.

18. Kankala RK, Chen BQ, Liu CG, Tang HX, Wang SB, Chen AZ. Solution-enhanced dispersion by supercritical fluids: an ecofriendly nanonization approach for processing biomaterials and pharmaceutical compounds. Int J Nanomed 2018;13:4227-45.

19. Aditya NP, Hamilton IE, Noon J, Norton IT. Microwave-assisted nanonization of poorly water-soluble curcumin. ACS Sustainable Chem Eng 2019;7:9771-81.

20. Sosnik A, Arzi RS. Electrohydrodynamic atomization and spraydrying for the production of pure drug nanocrystals and cocrystals. Adv Drug Delivery Rev 2018;131:79-100.

21. Fudholi A, Puspitasar IKA, Sopyan I, Muchtaridi M. A simple effort to enhance solubility and dissolution rate of simvastatin using co-crystallization. Int J Pharm Pharm Sci 2016;8:342-46.

22. Ellenberger DJ, Miller DA, Kucera SU, Williams III RO. Improved vemurafenib dissolution and pharmacokinetics as an amorphous solid dispersion produced by kinetisol processing. AAPS PharmSciTech 2018;19:1957-70.

23. Sekiguchi K, Obi N. Studies on the absorption of eutectic mixture. I. A comparison of the behavior of eutectic mixture of sulfathiazole and that of ordinary sulfathiazole in man. Chem Pharm Bull 1961;9:866-72.

24. Ghareeb MM, Abdulrasool AA, Hussein AA, Noordin MI. Kneading technique for preparation of solid binary dispersion of meloxicam with poloxamer 188. AAPS PharmSciTech 2009:10:1206-15.

25. Licciardi M, Mohac LMD, Abraham BR, Caruana R, Gaetano G. Multicomponent solid dispersion a new generation of solid dispersion produced by spray-drying. J Drug Delivery Sci Technol 2020;57:101750

26. Abraham BTR, Mohac LMD, Keating AV, Pina MDF. Review: engineering of nanofibrous amorphous and crystalline solid dispersions for oral drug delivery. Pharmaceutics 2018;11:1-10.

27. Yan HM, Jia XB, Zhang ZH, Jiang YR, Ding DM. An attempt to stabilize tanshinone IIA solid dispersion by the use of ternary systems with nano- $\mathrm{CaCO} 3$ and poloxamer 188. Pharmacogn Mag 2014;10:S311-7.

28. Davis M. Recent strategies in spray drying for the enhanced bioavailability of poorly water-soluble drugs. J Controlled Release 2017;269:110-27.

29. Atef E, Prasad D, Chauhan H. Amorphous stabilization and dissolution enhancement of amorphous ternary solid dispersions: combination of polymers showing drug-polymer interaction for synergistic effects. J Pharm Sci 2014;103:3511-23.

30. Mooter GVD, Singh A. Spray drying formulation of amorphous solid dispersions. Adv Drug Delivery Rev 2015;100:27-50.

31. Pan B, Sun W. Effect of micro-environment modification and polymer type on the in vitro dissolution behavior and in vivo performance of amorphous solid dispersions. Eur J Pharm Sci 2017;104:240-54

32. Fule RA, Meer TS, Sav AR, Amin PD. Artemether soluplus hotmelt extrudate solid dispersion systems for solubility and dissolution rate enhancement with amorphous State characteristics. J Pharm 2013;1514:32.

33. Hanada M, Jermain SV, Williams III RO. Enhanced dissolution of a porous carrier containing ternary amorphous solid dispersion system prepared by a hot-melt method. J Pharm Sci 2018:107:362-71

34. Lang B, Liu S, Mcginity JW, William III RO. Effect of hydrophilic additives on the dissolution and pharmacokinetic properties of itraconazole-enteric polymer hot-melt extruded amorphous solid dispersions. Drug Dev Ind Pharm 2016;42:429-45.

35. Tran TTD, Ngo HV, Nguyen PK, Vo TV, Duan W, Tran VT, et al. Hydrophilic-hydrophobic polymer blend for modulation of crystalline changes and molecular interactions in solid dispersion. Int J Pharm 2016;513:148-52.
36. Sahoo AC, Dinda SC, Kanungo SK, Panda J, Patro CN Formulation development of solid dispersions of nateglinide using melt-able hydrophilic carrier. Pharm Lett 2017;9:134-47.

37. Bourgeois S, Loys ZS, Valour JP, Briancon S, Fessi H. Orodispersible films based on amorphous solid dispersions of tetrabenazine. Int J Pharm 2017;518:242-52.

38. Setyawan D, Dewi MY, Isadiartuti D. Ternary solid dispersion to improve solubility and dissolution of meloxicam. J Basic Clin Physiol Pharmacol 2019;30:1-8.

39. Szafraniec J, Antosik A, Kurek M, Jachowicz R, Gawlak K, Odrobinska J, et al. The self-assembly phenomenon of poloxamers and its effect on the dissolution of a poorly soluble drug from solid dispersions obtained by solvent methods. Pharmaceutics 2019;11:1-22.

40. Moes JJ, Nuijen B, Koolen SLW, Huitema ADR, Schellens JHM, Beijnen JH. Pharmaceutical development and preliminary clinical testing of an oral solid dispersion formulation of docetaxel (Modradoc001). Int J Pharm 2011;420:244-50.

41. Kang MJ, Jung HJ, Ahn HI, Park JY, Ho MJ, Lee DR, et al. Improved oral absorption of tacrolimus by a solid dispersion with hypromellose and sodium lauryl sulfate. Int J Biol Macromol 2016;83:282-7.

42. Medarevic DP, Kleinebudde P, Djuris J, Djuric Z, Ibric S. Combined application of mixture experimental design and artificial neural networks in the solid dispersion development. Drug Dev Ind Pharm 2016;42:382-402.

43. Zhang Y, Luo R, Chen Y, Ke X, Hu D, Han M. Application of carrier and plasticizer to improve the dissolution and bioavailability of poorly water-soluble baicalein by hot melt extrusion. AAPS PharmsciTech 2014;15:560-8.

44. Taylor LS, Giraldo M, Laura I, Trasi NS. Impact of surfactants on the crystal growth of amorphous celecoxib. Int J Pharm 2014;461:251-7.

45. Brandl M, Frank KJ, Westedt U, Rosenblatt KM, Holig P, Rosenberg J, et al. The amorphous solid dispersion of the poorly soluble ABT-102 forms nano/microparticulate structures in aqueous medium: impact on solubility. Int J Nanomed 2012;7:5757-68.

46. Puchkov M, Huwyler J, Detampel P, Bauer SP, Schittny A Mechanistic insights into effect of surfactants on oral bioavailability of amorphous solid dispersions. J Controlled Release 2020;320:214-25.

47. Serajuddin ATM, Shah AV, Gumaste SG, Tahsin MD, Lam K, Solanki NG. Effects of surfactants on Itraconazole-HPMCAS solid dispersion prepared by hot-melt extrusion I: miscibility and drug release. J Pharm Sci 2019;108:1453-65.

48. Dave RH, Patel AD, Donahue E, Patel HH. To evaluate the effect of addition of an anionic surfactant on solid dispersion using model drug indomethacin. Drug Dev Ind Pharm 2011;38:930-9.

49. Hirsch M. Surface active agents (surfactants). Prospector; 2015. Available from: https://knowledge.ulprospector.com/3106/pc-surface-activeagents-surfactants [Last accessed on 20 Dec 2020]

50. Dave N, Joshi T. A concise review on surfactants and its significance. Int J Appl Chem 2017;13:663-72.

51. Su W, Tang J, Bao J, Shi X, Sheng X. Preparation, optimization, and in vitro-in vivo evaluation of febuxostat ternary solid dispersion. J Microencapsulation 2018;35:454-66.

52. Chaudhari SP, Dugar RP. Application of surfactants in solid dispersion technology for improving solubility of poorly water soluble drugs. J Drug Delivery Sci Technol 2017;41:68-77.

53. Patel DM, Patel SP, Patel CN. Formulation and evaluation of fast dissolving tablet containing domperidone ternary solid dispersion. Int J Pharm Invest 2014;4:174-82.

54. Velaga S, Alhayali A, Tavellin S. Dissolution and precipitation behavior of ternary solid dispersions of ezetimibe in biorelevant media. Drug Dev Ind Pharm 2017;43:79-88.

55. Ali AA, Zaki RM, Menshawi SFE, Bary AA. Effect of binary and ternary solid dispersions prepared by fusion method on the dissolution of poorly water-soluble diacerein. Int J Drug Delivery 2013;5:99-109.

56. Alaziz DMA, Nesseem DI, Sammour OA, AllahElshamy AEA. Enhancement of solubility and dissolution rate of poorly watersoluble domperidone by the formulation of multicomponent 
solid dispersions using solvent evaporation method. Int J Pharm Sci Rev Res 2013;20:10-9.

57. Han HK, Bajracharya $r$, Lee SH, Song JG, Kim M, Lee K. Development of a ternary solid dispersion formulation of LW6 to improve the in vivo activity as a BCRP inhibitor: preparation and in vitro/in vivo characterization. Pharmaceutics 2019;11:206.

58. Sriamornsak P, Chamsai B, Limmatvapirat S, Sungthongjeen S. Enhancement of solubility and oral bioavailability of manidipine by the formation of ternary solid dispersion with $D$ - $\alpha$-tocopherol polyethylene glycol 1000 succinate and copovidone. Drug Dev Ind Pharm 2017;43:2064-75.

59. Kim DD, Lee JY, Kang WS, Piao J, Yoon IS, Cho HJ. Soluplus®/TPGSbased solid dispersions prepared by hot-melt extrusion equipped with twin-screw systems for enhancing oral bioavailability of valsartan. Drug Des Dev Ther 2015;9:2745-56.

60. Mao S, Guan J, Jin L, Liu Q, Xu H, Wu H, et al. Exploration of supersaturable lacidipine ternary amorphous solid dispersion for enhanced dissolution and in vivo absorption. Eur J Pharm Sci 2019;139:105043

61. Xiong S, Chen J, Chen Y, Huang W, Wang H, Du Y. Bottom up and top down approaches to explore sodium dodecyl sulfate and soluplus on the crystallization inhibition and dissolution of felodipine extrudates. J Pharm Sci 2018;107:2366-76.

62. Stulzer HK, Franca MT, Pereira RN, Riekes MK, Pinto JMO. Investigation of novel supersaturating drug delivery systems of chlorthalidone: the use of the polymer-surfactant complex as an effective carrier in solid dispersions. Eur J Pharm Sci 2018;111:142-52.

63. Lee BJ, Tran PHL, Dinh TT, Lee KH, Kim DJ. Dissolutionmodulating mechanism of $\mathrm{pH}$ modifiers in solid dispersion containing weakly acidic or basic drugs with poor water solubility. Expert Opin Drug Delivery 2010;7:647-61.

64. Onoue S, Taniguchi C, Kawabata Y, Wada K, Yamada S. Microenvironmental $\mathrm{pH}$-modification to improve dissolution behavior and oral absorption for drugs with $\mathrm{pH}$-dependent solubility. Expert Opin Drug Delivery 2014;11:505-16.

65. Yong CS, Kim JO, Marasini N, Tran TH, Poudel BK, Cho HJ, et al. Fabrication and evaluation of $\mathrm{pH}$-modulated solid dispersion for telmisartan by spray-drying technique. Int J Pharm 2013;441:424-32.

66. Lee BJ, Ha NS, Tran TTD, Tran PHL, Park JB. Dissolutionenhancing mechanism of alkalizers in poloxamer-based solid dispersions and physical mixtures containing poorly watersoluble valsartan. Chem Pharm Bull 2011;59:844-50.

67. Park JS, Jeong HM, Choi JS, Kwon SH, Lee SE, Byeon JC, et al. Use of acidifier and solubilizer in tadalafil solid dispersion to enhance the in vitro dissolution and oral bioavailability in rats. Int J Pharm 2017;526:77-87.

68. Jain S, Nagori BP, Yadav SK. Improvement of the dissolution behavior of the poorly water-soluble drug diacerein by solid dispersion technology and its formulation into tablet dosage form. Madridge J Nov Drug Res 2018;2:79-89.

69. Pan W, Li S, Wang X, Wang Y, Zhao Q, Zhang L, et al. A novel osmotic pump-based controlled delivery system consisting of $\mathrm{pH}$-modulated solid dispersion for poorly soluble drug flurbiprofen: in vitro and in vivo evaluation. Drug Dev Ind Pharm 2015;41:2089-99.

70. Park JS, Choi JS, Byeon JC. Naftopidil-fumaric acid interaction in a solid dispersion system: Improving the dissolution rate and oral absorption of naftopidil in rats. Mater Sci Eng C 2019;95:264-74.

71. Yang J, Dong L, Mai Y, Liu Q, Zhang W. Mechanism and improved dissolution of glycyrrhetinic acid solid dispersion by alkalizers. Pharmaceutics 2020;12:82.

72. Onoue S, Halder S, Tabata A, Seto Y, Seto H. Amorphous solid dispersions of carvedilol along with $\mathrm{pH}$-modifiers improved pharmacokinetic properties under hypochlorhydoria. Biopharm Drug Dispos 2018;39:232-42.

73. Han HK, Lee SH, Lee YS, Song JG. Improved in vivo effect of chrysin as an absorption enhancer via the preparation of ternary solid dispersion with Brij L4 and aminoclay. Curr Drug Delivery 2019;6:86-92.
74. Choi YW, Chae JS, Chae BR, Shin DJ, Goo YT, Lee ES, et al. Tablet formulation of a polymeric solid dispersion containing amorphous alkalinized telmisartan. AAPS PharmSciTech 2018;19:2990-9.

75. Wairkar S, Gaud R, Jadhav N. Enhanced dissolution and bioavailability of nateglinide by microenvironmental $\mathrm{pH}$-regulated ternary solid dispersion: in-vitro and in-vivo evaluation. J Pharm Pharmacol 2017;69:1099-109.

76. Pan B, Sun W. Effect of micro-environment modification and polymer type on the in vitro dissolution behavior and in vivo performance of amorphous solid dispersions. Eur J Pharm Sci 2017;104:240-54.

77. Park JB, Park YJ, Kang CY, Lee BJ. Modulation of microenvironmental $\mathrm{pH}$ and utilization of alkalizers in crystalline solid dispersion for enhanced solubility and stability of clarithromycin. Arch Pharm Res 2015;38:839-48.

78. Su W, Zhong $\mathrm{L}, \mathrm{Zhu} \mathrm{X}, \mathrm{Yu}$ B. Influence of alkalizers on dissolution properties of telmisartan in solid dispersions prepared by cogrinding. Drug Dev Ind Pharm 2014;40:1660-9.

79. Gao C, Yang $\mathrm{M}$, He S, Fan Y, Wang Y, Ge Z, et al. Microenvironmental $\mathrm{pH}$-modified solid dispersions to enhance the dissolution and bioavailability of poorly water-soluble weakly basic GT0918, a developing anti-prostate cancer drug: preparation, characterization and evaluation in vivo. Int J Pharm 2014;475:97-109.

80. Repka MA, Kim DW, Sarabu S, Shankar V, Bandari S, Murthy N, et al. Formulation of aripiprazole-loaded pH-modulated solid dispersions via hot-melt extrusion technology: in vitro and in vivo studies. Int J Pharm 2019;554:302-11.

81. Khang G, Shim JB, Lee JK, Jo H, Hwang JH, Jeong SM, et al. Effect of acidifier on the dissolution property of a solid dispersion of raloxifene HCl. Macromol Res 2013;21:42-8.

82. Onoue S, Kojo Y, Matsunaga S, Suzuki H, Taniguchi C, Kawabata $\mathrm{Y}$, et al. Improved dissolution of dipyridamole with the combination of pH-modifier and solid dispersion technology. Chem Pharm Bull 2017;65:426-31.

83. Reilly NJO, Baghel S, Cathcart H. Polymeric amorphous solid dispersions: a review of amorphization, crystallization, stabilization, solid-state characterization, and aqueous solubilization of biopharmaceutical classification system class II drugs. J Pharm Sci 2016;105:2527-44.

84. Mooter GVD. The use of amorphous solid dispersions: a formulation strategy to overcome poor solubility and dissolution rate. Drug Discovery Today Technol 2012;9:79-85.

85. Otsuka M, Nishimoto Y, Hattori Y. Characterization of ternary amorphous solid dispersion containing hypromellose phthalate and erythritol prepared by hot-melt extrusion using melting point depression. J Drug Delivery Sci Technol 2020;58:101797.

86. Andrews GP, Abudiak OA, Jones DS. An investigation into the dissolution properties of celecoxib melt extrudates: understanding the role of polymer type and concentration in stabilizing supersaturated drug concentrations. Mol Pharmaceutics 2011;8:1362-71.

87. Taylor LS, Xie T. Effect of temperature and moisture on the physical stability of binary and ternary amorphous solid dispersions of celecoxib. J Pharm Sci 2016;106:100-10.

88. Atef E, Chauhan H, Kuldipkumar A, Barder T, Medek A, Gu CH. Correlation of inhibitory effects of polymers on indomethacin precipitation in solution and amorphous solid crystallization based on molecular interaction. Pharm Res 2014;31:500-15.

89. Wagner KG, Monschke M. Impact of HPMCAS on the dissolution performance of polyvinyl alcohol celecoxib amorphous solid dispersions. Pharmaceutics 2020;12:541.

90. Albadarin AB, Potter CB, Davis MT, Iqbal J, Korde S, Pagire S, et al. Development of stability-enhanced ternary solid dispersions via combinations of HPMCP and soluplus processed by hotmelt extrusion. Int J Pharm 2017;532:603-11.

91. Shi X, Xu T, Huang W, Fan B, Sheng X. Stability and bioavailability enhancement of telmisartan ternary solid dispersions: the synergistic effect of polymers and drugpolymer(s) interactions. AAPS PharmSciTech 2019;20:143.

92. Ziaee A, Albadarin AB, Padrela L, Faucher A, Reilly EO, Walker G. Spray drying ternary amorphous solid dispersions of ibuprofen-an 
investigation into critical formulation and processing parameters. Eur J Pharm Biopharm 2017;120:43-51.

93. Bilgili E, Radgman K, Ahmad S, Tarabokija J, Coelho A, Rahman M. Synergistic and antagonistic effects of various amphiphilic polymer combinations in enhancing griseofulvin release from ternary amorphous solid dispersions. Eur J Pharm Sci 2020;150:105354

94. Baghel S, Cathcart H, Reilly NJO. Investigation into the solidstate properties and dissolution profile of spray-dried ternary amorphous solid dispersions: a rational step toward the design and development of a multicomponent amorphous system. Mol Pharm 2018;15:3796-812.

95. Mooter GVD, Meeus J, Lenaerts M, Scurr DJ, Amssoms K, Davies $\mathrm{MC}$, et al. The influence of spraydrying parameters on phase behavior, drug distribution, and in vitro release of injectable microspheres for sustained release. J Pharm Sci 2015;104:1451-60.

96. Maitani Y, Sakurai A, Sakai T, Sako K. Polymer combination increased both physical stability and oral absorption of solid dispersions containing a low glass transition temperature drug: physicochemical characterization and in vivo study. Chem Pharm Bull 2012;60:459-64.

97. Khang G, Lee JH, Kim MJ, Yoon H, Shim CR, Ko HA, et al. Enhanced dissolution rate of celecoxib using PVP and/or HPMC-based solid dispersions prepared by spray-drying method. J Pharm Invest 2013;43:205-13

98. Moribe K, Ohyagi N, Ueda K, Higashi K, Yamamoto K, Kawakami K. Synergetic role of hypromellose and methacrylic acid copolymer in the dissolution improvement of amorphous solid dispersions. J Pharm Sci 2017;106:1042-50.

99. Badry ME. Physicochemical characterization and dissolution properties of meloxicam-gelucire 50/13 binary systems. Sci Pharm 2011;79:375-86.

100. Chella N, Tadikonda R. Melt dispersion granules: formulation and evaluation to improve oral delivery of poorly soluble drugs-a case study with valsartan. Drug Dev Ind Pharm 2014:41:888-97.

101. Panda TK, Das D, Panigrahi L. Formulation development of solid dispersions of bosentan using gelucire 50/13 and poloxamer 188. J Appl Pharm Sci 2016;6:27-33.
102. Shinde VR, Pore YV, Rao JV. Physical stabilization of amorphous itraconazole in solid dispersions for improved dissolution profile. J Appl Pharm Sci 2016;6:37-44.

103. Censi R, Gigliobianco MR, Dubbini A, Malaj L, Martino PD. New nanometric solid dispersions of glibenclamide in neusilin UFL2. AAPS PharmSciTech 2016;17:1204-12.

104. Serajuddin ATM, Shah A. Conversion of solid dispersion prepared by acid-base interaction into 3 free-flowing and tabletable powder by using Neusilin US2. Int J Pharm 2015;484:172-80

105. Cho CW, Kim SJ, Na YG, Bang KH, Lee HJ, Wang M, et al. A novel composition of ticagrelor by solid dispersion technique for increasing solubility and intestinal permeability. Int J Pharm 2019;555:11-8.

106. Sruti J, Patra CN, Swain S, Panigrahi KC, Patro AP, Beg S, et al. Improvement in the dissolution rate and tableting properties of cefuroxime axetil by melt-granulated dispersion and surface adsorption. Acta Pharm Sin B 2013;3:113-22.

107. Lee J, Jo K, Cho JM, Lee H, Kim EK, Kim HC, et al. Enhancement of aqueous solubility and dissolution of celecoxib through phosphatidylcholine-based dispersion systems solidified with adsorbent carriers. Pharmaceutics 2018;11:1.

108. Medarevic D, Vojinovic T, Vranic E, Potpara Z, Krstic M, Djuris J, et al. Development of ternary solid dispersions with hydrophilic polymer and surface adsorbent for improving dissolution rate of carbamazepine. Saudi Pharm J 2018;26:725-32.

109. Teixeira CCC, Mendonca LM, Bergamaschi MM, Queiroz RHC, Souza GEP, Antunes LMG, et al. Microparticles containing curcumin solid dispersion: stability, bioavailability and antiinflammatory activity. AAPS PharmSciTech 2016;17:252-61.

110. Sriamornsak P, Kontong S, Weerapol Y, Nunthanid J, Sungthongjeen S, Limmatvapirat S. Manufacture of ternary solid dispersions composed of nifedipine, eudragit $\mathrm{E}$ and adsorbent. Adv Mater Res 2011;317:185-8.

111. Kaushik D, Singh N, Arora A. Enhancement of dissolution profile of gliclazide by solid dispersion adsorbates. Latt Am J Pharm 2011;30:2057-60.

112. Mahajan A, Surti N, Koladiya P. Solid dispersion adsorbate technique for improved dissolution and flow properties of lurasidone hydrochloride: characterization using 32 factorial design. Drug Dev Ind Pharm 2018;44:463-71. 